\title{
Pu-erh Tea Protects the Nervous System by Inhibiting the Expression of Metabotropic Glutamate Receptor 5
}

\author{
Chunjie $\mathrm{Li}^{1,2} \cdot$ Shaomeng Chai ${ }^{1,2} \cdot$ Yongzhi Ju${ }^{1,2} \cdot \mathrm{Lu} \mathrm{Hou}^{1,2} \cdot \mathrm{Hang}^{\mathrm{Zhaoo}}{ }^{1,2} \cdot \mathrm{Wei} \mathrm{Ma}^{4}$. \\ Tian $\mathrm{Li}^{5} \cdot$ Jun Sheng ${ }^{2,3} \cdot$ Wei Shi ${ }^{1,2}$ (D)
}

Received: 31 March 2016/Accepted: 17 August 2016 / Published online: 30 August 2016

(C) The Author(s) 2016. This article is published with open access at Springerlink.com

\begin{abstract}
Glutamate is one of the major excitatory neurotransmitters of the CNS and is essential for numerous key neuronal functions. However, excess glutamate causes massive neuronal death and brain damage owing to excitotoxicity via the glutamate receptors. Metabotropic glutamate receptor 5 (mGluR5) is one of the glutamate receptors and represents a promising target for studying neuroprotective agents of potential application in neurodegenerative diseases. Pu-erh tea, a fermented tea, mainly produced in Yunnan province, China, has beneficial effects, including the accommodation of the CNS. In this study, pu-erh tea markedly decreased the transcription and translation of mGluR5 compared to those by black and green teas. Pu-erh tea also inhibited the expression of Homer, one of the synaptic scaffolding proteins binding to mGluR5. Pu-erh tea protected neural cells from necrosis via blocked $\mathrm{Ca}^{2+}$ influx and inhibited protein kinase C (PKC) activation induced by excess glutamate. Pu-erh tea relieved rat epilepsy induced by LiCl-pilocarpine in behavioural and physiological assays. Pu-erh tea also decreased the expression of mGluR5 in the hippocampus. These results show that the
\end{abstract}

Wei Shi

shiw@jlu.edu.cn

1 Key Laboratory for Molecular Enzymology and Engineering, Ministry of Education, Jilin University, Changchun 130012, China

2 College of Life Science, Jilin University, No. 2699 Qianjin Street, Jilin Province. Rm. 226 Life Science Building, Changchun 130012, China

3 Yunnan Research Centre for Advanced Tea Processing, Yunnan Agricultural University, Kunming 650201, China

4 Internal Medicine-Cardiovascular Department in China-Japan Union Hospital, Jilin University, Changchun 130012, China

5 School of Science and Technology in Changchun University of Science and Technology, Changchun 130012, China inhibition of mGluR5 plays a role in protecting neural cells from glutamate. The results also indicate that pu-erh tea contains biological compounds binding transcription factors and inhibiting the expression of mGluR5 and identify pu-erh tea as a novel natural neuroprotective agent.

Keywords Pu-erh tea $\cdot$ Glutamate $\cdot$ mGluR5 ·

Neurodegenerative diseases

\section{Introduction}

Glutamate, the primary excitatory neurotransmitter in the brain, plays various physiological roles in cognition, memory and perception via the activation of multiple receptors [1]. An increase in the extracellular levels of glutamate leads to disorganised neuronal spike activity, impairing the processing of relevant information in the brain [2]. Glutamate binding metabotropic glutamate receptors (mGluRs) are one of Gprotein-coupled receptors and exert its physiological roles through intracellular chemical-messenger signalling cascades [3]. Eight mGluRs (mGluR1-8) have been discovered and are grouped into three categories: group I (mGluR1 and 5), group II (mGluR2 and 3) and group III (mGluR4, 6, 7 and 8) according to sequence identity, pharmacological properties and downstream activation [4]. In general, mGluR5 combined with glutamate activates the G-protein $\mathrm{Gq} / 11$, and subsequently the activated G-protein activates phospholipase C (PLC) which hydrolyses membrane phosphoinositides to form inositol 1, 4, 5-triphosphate (IP3) and diacylglycerol (DAG). IP3 causes the release of intracellular calcium, which activates PKC [5]. The Homer family binds to the intracellular Cterminal tail of mGluR5 and also excites downstream effectors (Fig. 1) [6]. It is noteworthy that mGluR5 regulates various mechanisms implicated in neurogenesis and synaptic 
Fig. 1 Schematic of mGluR5 signalling pathway

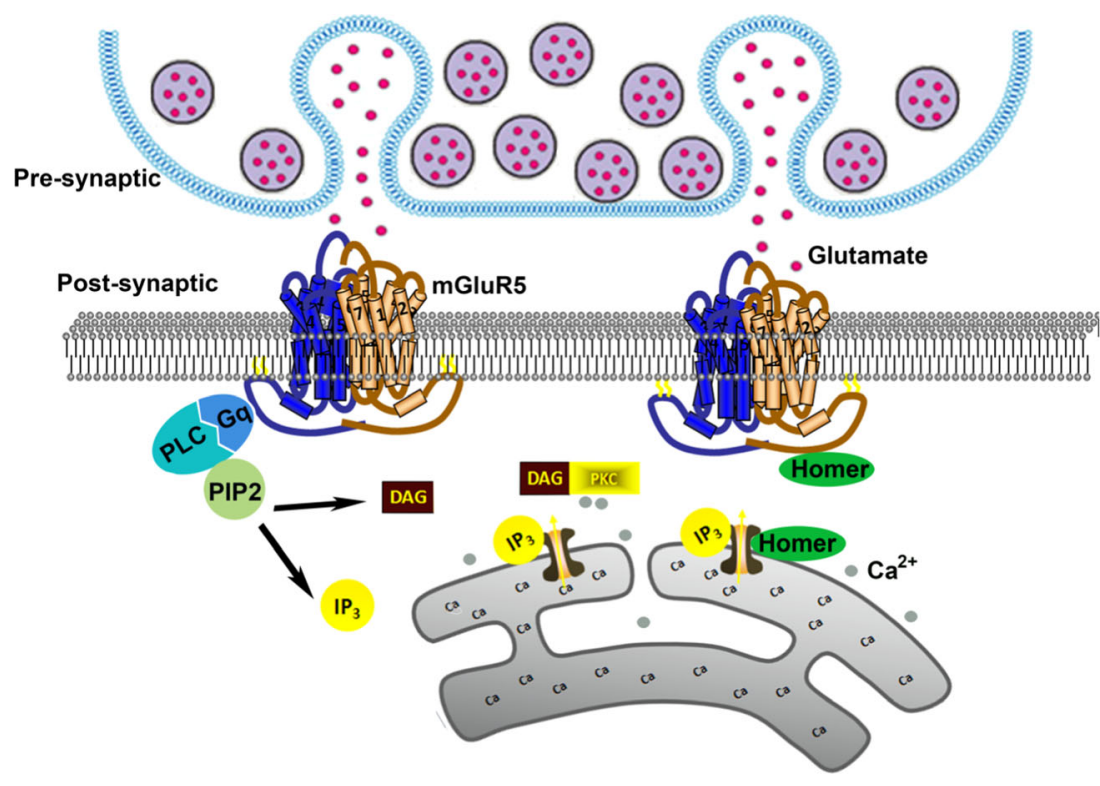

maintenance, and the abnormal regulation of mGluR5 has been implicated in the pathophysiology of many neurological and psychiatric disorders, including pain, epilepsy, schizophrenia, drug addiction and Alzheimer's disease [7]. Thus, mGluR5 represents a pathophysiological hallmark for neuroprotective agents of potential application in neurodegenerative disorders [8].

Epilepsy is the second most common neurological disorder after stroke and a major burden for public health systems, afflicting worldwide approximately about 65 million people [9]. Although current antiepileptic drugs have achieved complete seizure control, they do not prevent or eliminate the substantial behavioural, cognitive and somatic comorbidities in many epilepsy patients [10]. New drugs with fewer side reactions and greater efficacy are urgently needed. Epilepsy researchers have recently embarked on a revitalise effort to move from targeting the control of symptoms to strategies of prevention and cure. One important direction for new therapeutics is identifying new molecular targets [11].

Tea is one of the most popular beverages in the world owing to its refreshing taste and attractive aroma. Its possible beneficial health functions have recently received much research attention. Pu-erh tea, a fermented tea, produced mainly in Yunnan province of China, is obtained by first drying crude green tea leaves (Camellia sinensis var. assamica (L.) O. Kuntze; Theaceae) and then subjecting them to secondary fermentation by microorganisms, such as Aspergillus sp., resulting in a unique type of tea [12]. Several studies have reported that pu-erh tea has shown a wide range of biological effects, such as inhibiting nitric oxide production [13], promoting weight loss [14], reducing blood lipids [15], exerting antimicrobial and antitumor activities $[16,17]$ and scavenging free radicals [18]. We recently also found that pu-erh tea may reduce the incidence of epilepsy and amyotrophic lateral sclerosis $[19,20]$. These results suggest that the potential efficacy of pu-erh tea in the regulation of the nervous system.

In this study, we discovered that pu-erh tea downregulated the transcription and translation of mGluR5 by Affymetrix Expression microarrays experiments and Western blot. $\mathrm{Pu}-$ erh tea also protected SH-SY5Y cells against apoptosis induced by L-glutamate (L-Glu) and alleviated epilepsy behaviour by inhibiting the expression of mGluR5. The results identified mGluR5 as a target for the treatment of neurological and psychiatric disorders and suggested that pu-erh tea might be a potential natural source of protection against neurodegenerative diseases associated with mGluR5. Accordingly, the aim of this study was to identify the protective mechanisms of puerh tea against injury to neuronal cells in vitro and in vivo.

\section{Materials and Methods}

\section{Materials}

Adult male Wistar rats (4-5 weeks old) were obtained from the Animal Resource Center of Jilin University and housed at $22 \pm 2{ }^{\circ} \mathrm{C}$ in a controlled environment with a 12-h light and 12-h dark cycle. All rats were treated humanely and in compliance with the recommendations of the animal care committee of Jilin University. We used the minimum number of mice required to draw a conclusion and tried to minimise their suffering as much as possible.

3-(4, 5- Dimethylthiazol-2-yl)-2, 5-diphenyltetrazolium bromide (MTT), and dimethyl sulfoxide (DMSO), L-Glu were purchased from Sigma. Cell culture media, Dulbecco's modified Eagle's medium (DMEM), heat-inactivated foetal bovine serum (FBS) and trypsin were supplied by Gibco. Antibodies were purchased from Santa Cruz (CA93446, 
USA). A Luciferase Reporter Gene Assay Kit was purchased from Beyotime. (RS)-2-Chloro-5-hydroxyphenylglycine (CHPG), a selective mGluR5 agonist and 2-Methyl6-(phenylethynyl)-pyridine (MPEP), a selective mGluR5 antagonist, were purchased from Selleckchem.

\section{Cell Culture}

The SH-SY5Y, HEK293T and 3 T3 cell lines were cultured in DMEM, and the Jurkat cell line was cultured in RPMI1640 medium supplemented with $10 \%$ FBS, 100 units $/ \mathrm{mL}$ penicillin and 100 units $/ \mathrm{mL}$ streptomycin (Invitrogen).

\section{Cytotoxicity Assay}

In the cytotoxicity assay, cells were seeded at a density of $1 \times 10^{4}$ cells/well in 96-well plates and incubated for $24 \mathrm{~h}$. Cells were treated with pu-erh tea at various concentrations for $24 \mathrm{~h}$. MTT $(5 \mathrm{mg} / \mathrm{mL}, 20 \mu \mathrm{L})$ was added to the medium $24 \mathrm{~h}$ later. After incubation at $37^{\circ} \mathrm{C}$ for $4 \mathrm{~h}$, the supernatant was aspirated and $100 \mu \mathrm{L}$ of DMSO was added to each well, followed by vibration for $10 \mathrm{~min}$. The absorbance in the experimental wells was measured at $570 \mathrm{~nm}$ with a microplate reader.

\section{Affymetrix Microarrays}

RNA was extracted with TRI reagent (Sigma) and DNAse I (Invitrogen) from Jurkat in triplicate with or without pu-erh tea treatment for $12 \mathrm{~h}$. RNA quality and concentration were assessed with an Agilent 2100 Bioanalyser and Nanodrop ND-1000. Data from Affymetrix 4302.0 microarray chips (SCIBLU, Affymetrix) was analysed with Arraystar 3 software (DNA STAR Inc.), which was quantile-normalised and processed by the RMA (Affymetrix) algorithm.

\section{Luciferase Assay}

Promoter regions were amplified by PCR amplification and subcloned into the KpnI/HindIII sites of the luciferase reporter vector pGL3-Basic (Promega) upstream of the firefly luciferase gene (Fig. 2). SH-SY5Y and HEK293T cells were transfected with mGluR5 promoter-pGL3 recombinant plasmid by electroporation according to the manufacturer's instructions. A monolayer of $80 \%$ confluent cells was trypsinised, washed with appropriate media and washed again in ice-cold PBS buffer. Cell suspension for the electroporation was first prepared in $400 \mu \mathrm{L}$ ice-cold PBS buffer $\left(2.5 \times 10^{6}\right.$ cells $/ \mathrm{mL}$ ) in a 0.4-cm electric rotary cup, followed by adding $10 \mu \mathrm{g}$ plasmid. The electroporation conditions were adopted from previous work, as follows: $\mathrm{U}=225 \mathrm{~V}, \mathrm{R}=\infty$, $\Omega=1050 \mu \mathrm{F}$. After electroporation, cells were seeded in 12well plates at a density of $4 \times 10^{4}$ cells per well. After $12 \mathrm{~h}$, transfected cells were incubated with pu-erh, black and green teas. Cells were then harvested and firefly luciferase activity was determined using a Sirius luminometer (Berthold Detection System). Experiments were performed in triplicates and repeated at least three times independently.

\section{Western Blot}

Cells were prepared in ice-cold lysis buffer $(100 \mathrm{mM} \mathrm{NaCl}$, $50 \mathrm{mM}$ Tris-HCl, $1 \mathrm{mM}$ EDTA, $10 \mathrm{mM} \mathrm{MgCl}$, $\mathrm{pH}$ 7.2) containing $1 \%$ Triton $\mathrm{X}-100$, phosphatase and protease inhibitor cocktail (Dinggguo, China) for $10 \mathrm{~min}$. Cell lysates were centrifuged at $12,000 \mathrm{~g}$ for $10 \mathrm{~min}$ at $4{ }^{\circ} \mathrm{C}$, and protein concentrations of supernatants were determined with BCA assay. Lysates were added $5 \times$ SDS containing $100 \mathrm{mM}$ DTT. Equal amounts of protein were loaded onto and separated on $12 \%$ SDS-PAGE gels and transferred to polyvinylidene fluoride (PVDF) membranes. Membranes were incubated with primary antibodies overnight, washed three times in washing buffer $(0.1 \%$ Tween-20 in PBS), incubated with HRPcoupled secondary antibodies for $1 \mathrm{~h}$, washed three times in washing buffer and developed using chemiluminescent HRP detection substrate. When proteins were extracted from hippocampus tissue, hippocampus tissues were placed in lysis buffer (as above) and homogenised for $1 \mathrm{~min}$. The homogenate was then centrifuged at $12,000 \mathrm{~g}$ for $10 \mathrm{~min}$ at $4{ }^{\circ} \mathrm{C}$. The final supernatant was collected and processed as above.

\section{Nuclear Staining with Hoechst 33342}

SH-SY5Y cells were seeded in 6-well plates $\left(1.5 \times 10^{5}\right.$ cells/ well) for $24 \mathrm{~h}$. Cells in a 6-well plate were incubated with puerh, black or green teas for $12 \mathrm{~h}$ before treatment with L-Glu for $24 \mathrm{~h}$. Cells were washed with PBS and stained with $500 \mu \mathrm{L}$ of Hoechst 33342 solution for $15 \mathrm{~min}$ at room temperature in the dark. The nuclear morphology of the cells was examined under a fluorescent microscope.

\section{Flow Cytometry Analysis of Apoptosis in SH-SY5Y}

SH-SY5Y cells were seeded in 6-well plates $\left(1.5 \times 10^{5}\right.$ cells/ well) for $24 \mathrm{~h}$. Cells in each 6-well plate were incubated with pu-erh, black or green teas for $12 \mathrm{~h}$ before treatment with LGlu for $24 \mathrm{~h}$. Cells treated with medium alone were used negative control. Apoptosis of cells was evaluated by measurement of the exposure of phosphatidylserine on the cell membranes using Apoptosis Detection Kits. Cell pellets were resuspended in a staining solution containing propidium iodide (PI) for $5 \mathrm{~min}$ and Annexin V-FITC for $15 \mathrm{~min}$ at room temperature in the dark. The cells were assessed by fluorescence-activated cell sorting (FACS) using the Cell Quest software (BD, Pharmingen). 
Fig. 2 Construction strategy and structure of the recombinant plasmid mGluR5 promoter-pGL3

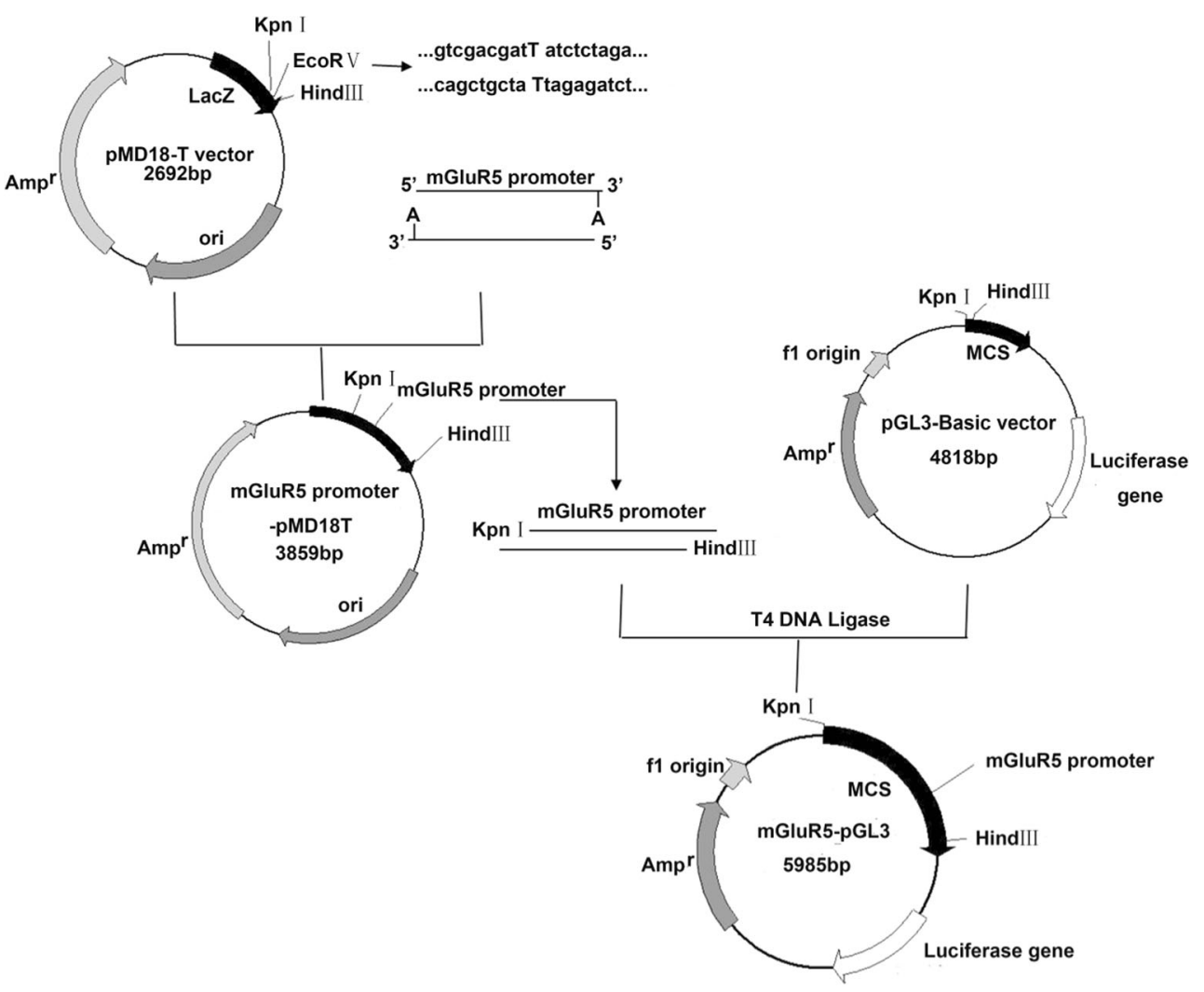

\section{Calcium Imaging}

SH-SY5Y cells were seeded in 6-well plates $\left(1.5 \times 10^{5}\right.$ cells/ well) for $24 \mathrm{~h}$. Cells in a 6-well plate were incubated with puerh, black, or green teas for $12 \mathrm{~h}$ before treatment with L-Glu for $24 \mathrm{~h}$. Cells treated with medium alone were used as negative control. Cells were loaded with $2 \mu \mathrm{M}$ Fluo-3 AM at $37^{\circ} \mathrm{C}$ for $1 \mathrm{~h}$. Cells were suspended in PBS after being washed three times and analysed by a flow cytometry device equipped with the Cell Quest software at $488 \mathrm{~nm}$.

\section{Epileptic Rat Model}

Status epilepticus (SE) was induced in adult Wistar rats by using Licl-pilocarpin [21]. Rats were randomly divided into 6 groups with 6 rats in each group. Three groups were administered intragastricly with pu-erh tea at a dose of $0.5 \mathrm{~g} / \mathrm{Kg} /$ day, the other three groups were treated with saline. After 20 days, lithium chloride was intraperitoneally injected into the four groups rats that two of them were dministered intragastricly with pu-erh tea, the other two were treated with saline at a $127 \mathrm{mg} / \mathrm{kg}$ dosage. After $18 \mathrm{~h}$, the rats were treated with a $40 \mathrm{mg} / \mathrm{kg}$ dose of pilocarpine, administered intraperitoneally. Two of the groups that one was treated with pu-erh tea and Licl-pilocarpin, the other was treated with saline and Liclpilocarpin were treated with $4 \mathrm{mg} / \mathrm{kg}$ diazepam, before pilocaroine administered intragastricly. Saline was administered to the control group at the same dosage.

\section{Behavioural Study}

Rats were video monitored from day 0 to day 15 post status epilepsy (SE) and were scored by an individual blind to the experimental design. Behavioural seizure was recorded according to a modification of the classification of Racine [22]: 0, exploring; 1 , immobility; 2 , rigid posture; 3 , head nodding; 4 , bilateral forelimb clonus and falling; 5 , continued clonus and falling; and 6, generalised tonus. Three behavioural patterns of SE could be recognised: I, initial (class 1-2), M, middle (class 3) and C, critical (class 4-6). Seizure number and type were recorded within $1 \mathrm{~h}$ of the seizure in day 0 . Then, seizure number and type were recorded $30 \mathrm{~min}$ every $24 \mathrm{~h}$ from day 1 to day 15 .

\section{Measurements of IP3 and DAG}

The measurement of the contents of IP3 and DAG was conducted using IP3 and DAG ELISA kits (RD, USA). Hippocampus tissues were placed in ice-cold PBS and homogenised for $1 \mathrm{~min}$. The homogenate was then centrifuged at $12,000 \mathrm{~g}$ for $10 \mathrm{~min}$ at $4{ }^{\circ} \mathrm{C}$. The final supernatant was collected. 


\section{Haematoxylin and Eosin (HE) Staining}

Brains were prepared from control and post-SE rats. Animals were anaesthetised using $20 \%$ urethane at a dose of $0.5 \mathrm{~mL} /$ $\mathrm{kg}$. Once deeply anesthetised, animals underwent heart perfusion with ice-cold modified PBS followed by $4 \%$ poly-formaldehyde. The brain was removed and dehydrated in 20 and $30 \%$ sucrose. The brains were then embedded in optimal cutting temperature compound (OCT). Six-micrometre-thick slices were made with a tissue slicer and stained in HE solutions to examine morphological changes.

\section{Immunofluorescence}

To detect the expression of mGluR5 in rat brains, $6-\mu \mathrm{m}$ paraffin sections were subjected to antigen retrieval and blocking of endogenous peroxidase activity, followed by incubation with mGluR5 monoclonal antibody (diluted at 1:200) overnight at $4{ }^{\circ} \mathrm{C}$. The sections were incubated with FITC-conjugated anti-mouse $\operatorname{IgG}(1: 250)$ for $2 \mathrm{~h}$ at room temperature. All images were acquired with a fluorescence microscope.

\section{Statistical Analysis}

All values were expressed as mean \pm S.D. A One-way analysis of variance (ANOVA) was used to detect statistical significance followed by post hoc multiple comparisons (Dunn's test) by GraphPad Prism 6.0. A value of $P<0.05$ was considered to be significant $[23,24]$.

\section{Results}

\section{Pu-erh Tea Down-Regulated the Transcription of mGluR5}

To investigate the cytotoxicity of pu-erh tea, cell viability assays were performed. Our finding demonstrated that puerh did not inhibit the proliferation of Jurkat or SH-SY5Y at concentrations lower than $250 \mu \mathrm{g} / \mathrm{mL}$, whereas it exerted a marked inhibitory effect on the proliferation of Jurkat and SH-SY5Y at concentrations greater than $0.5 \mathrm{mg} / \mathrm{mL}$. No inhibition was observed in 3 T3 (Fig. 3).

The messenger RNA (mRNA) expression differences between the Jurkat cells treated and untreated with pu-erh tea were detected with Affymetrix expression microarrays. The results showed that pu-erh tea could downregulate mGluR5, one of the $\mathrm{G}$ protein-coupled receptors implicated in the nervous system (Tables 1, 2).

\section{Pu-erh Tea Inhibited the Activity of mGluR5 Promoter}

To assess the role of pu-erh tea in transcriptional regulation and cell-specific expression of mGluR5, we constructed mGluR5 promoter-pGL3 recombinant plasmid The PCR products of the mGluR5 promoter were examined by $1 \%$ agarose gel electrophoresis (Fig. 4a). PCR product is $1167-$ bp specific fragment consistent with the mGluR5 promoter. The promoter region was then subcloned into the KpnI/ HindIII sites of pGL3-Basic. Double enzyme digestion reaction yielded a clear obvious 1167-bp fragment, showing that a recombinant plasmid, mGluR5 promoter-pGL3 had been constructed (Fig. 4b).

Thus, the following detection on the activity of mGluR5 promoter to drive the expression of luciferase was assessed in HEK293T and SH-SY5Y cells. Luciferase activity driven by mGluR 5 promoter was decreased significantly at a concentration of $62.5 \mu \mathrm{g} / \mathrm{mL}$ (Fig. 4c). The transfected cells were then incubated at this concentration for various times, with the result that at $6 \mathrm{~h}$ luciferase activity was decreased significantly (Fig. 4d). Compared to black and green teas, treatment with pu-erh tea for $6 \mathrm{~h}$ had a greater suppressive effect on transcriptional regulation of mGluR5 in both HEK293T and SHSY5Y cells (Fig. 4e, f).

\section{Pu-erh Tea Inhibited the Expression of mGluR5}

To further validate the inhibition of the expression of the mGluR5, several concentrations of pu-erh tea, $50 \mu \mathrm{M}$ a

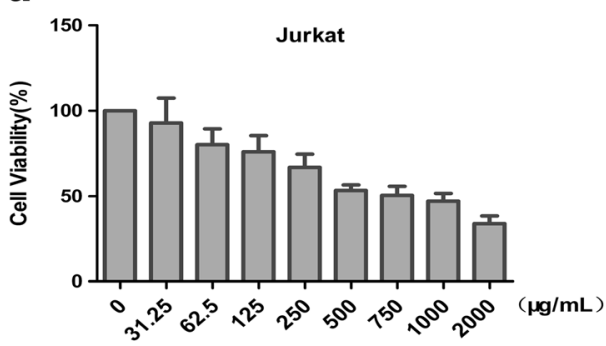

b

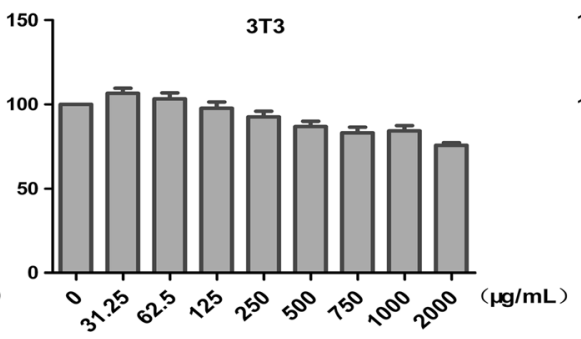

C

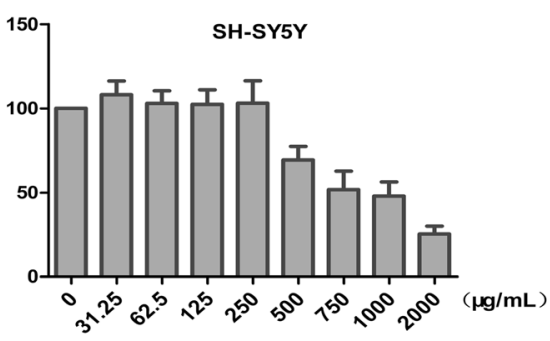

Fig. 3 a Jurkat cell viability after incubation with various concentration of pu-erh tea for $24 \mathrm{~h}$. b $3 \mathrm{~T} 3$ cell viability after incubation with various concentration of pu-erh tea for $24 \mathrm{~h}$. c SH-SY5Y cell viability after incubation with various concentration of pu-erh tea for $24 \mathrm{~h}$. Data were analysed using the GraphPad Prism software $(n=6)$ 
Table 1 Pu-erh tea extract increased the expression of target genes

\begin{tabular}{lcl}
\hline UniGene.ID & Fold change & Gene. title \\
\hline Hs.520028 & 14.54148 & Heat shock 70 kDa protein 1 A \\
Hs.654614 & 10.09114 & Heat shock 70 kDa protein 6 \\
Hs.591670 & 6.948213 & Inhibitor of DNA binding 2 \\
Hs.658815 & 6.465138 & Transcribed locus \\
Hs.525704 & 5.117358 & Jun oncogene \\
Hs.155569 & 4.549088 & ChaC \\
Hs.370699 & 3.700921 & Hypothetical protein LOC284801 \\
\hline
\end{tabular}

CHPG (a selective mGluR5 agonist) and $50 \mu \mathrm{M}$ MPEP (a selective mGluR5 antagonist) were added to SH-SY5Y cells and followed by incubation for $12 \mathrm{~h}$. There were no effects on the growth of SH-SY5Y at the concentration of $62.5 \mu \mathrm{g} / \mathrm{mL}$ (Fig. 3c). The expression of mGluR5 was markedly reduced compared to the control when cells were treated with $62.5 \mu \mathrm{g} /$ $\mathrm{mL}$ of pu-erh tea for $12 \mathrm{~h}$ compared to the control (Fig. 5a, b). When SH-SY5Y cells were treated with $62.5 \mu \mathrm{g} / \mathrm{mL}$ of pu-erh tea for various times, pu-erh tea markedly inhibited the expression of mGluR5 compared to the control (Fig. 5d, e). Compared to black and green teas, treatment with pu-erh tea for $12 \mathrm{~h}$ significantly inhibited the expression of mGluR5 (Fig. $5 \mathrm{~g}, \mathrm{~h}$ ).

The Homer family of proteins is localised predominantly at the postsynaptic density (PSD) in mammalian neurons and binds a specific proline-rich sequence on group I mGluRs. We assayed the expression of Homer by Western blot, and found that Homer was also significantly inhibited by pu-erh tea at dose-dependently and time-dependently (Fig. 5).

Table 2 Pu-erh tea extract decreased the expression of the target gene

\begin{tabular}{lll}
\hline UniGene.ID & Fold change & Gene. title \\
\hline Hs.188859 & -1.705 & G protein-coupled receptor 20 \\
Hs.446091 & -1.705 & Wilms tumour 1 associated protein \\
Hs.631992 & -1.717 & Dystonin \\
Hs.122125 & -1.719 & Transcribed locus \\
Hs.697691 & -1.77 & Olfactory receptor \\
Hs.370036 & -1.805 & Chemokine (C-C motif) receptor 7 \\
Hs.135232 & -1.817 & Transcribed locus \\
Hs.147361 & -1.936 & Metabotropic glutamate receptor 5 \\
Hs.224012 & -1.995 & Jagged 1 (Alagille syndrome) \\
Hs.5462 & -2.017 & Solute carrier family 4 \\
Hs.1466 & -2.039 & Glycerol kinase \\
Hs.660607 & -2.073 & Oestrogen receptor 2 (ER beta) \\
Hs.76884 & -2.317 & Inhibitor of DNA binding 3 \\
Hs.504609 & -4.464 & Inhibitor of DNA binding 1 \\
\hline
\end{tabular}

\section{Effects of Pu-erh Tea on Neuronal Injury}

Increase in extracellular levels of glutamate leads to activation of mGluR5 and a strong excitatory neurotoxicity, resulting in neuronal swelling and necrosis. To confirm that pu-erh tea protects cells from nerve injury, SH-SY5Y cells were incubated with pu-erh tea before treatment with L-glutamate (L-Glu). The nuclear morphology of SH-SY5Y cells was examined after staining with Hoechst 33342. Compared to black and green teas, 12 -h treatment with $62.5 \mu \mathrm{g} / \mathrm{mL}$ of pu-erh tea reduced the number of hallmarks of apoptosis induced by $160 \mathrm{mM}$ L-Glu, whereas the mGluR5 agonist CHPG increased and the mGluR5 antagonist MPEP decreased the number of apoptosis (Fig. 6a).

To further investigate whether pu-erh tea protects cells against apoptosis, the cells were analysed by flow cytometry after staining with Annexin V-FITC and PI. The percentage of surviving cells increased from 28.36 to $71.99 \%$ after 12 -h of treatment with pu-erh tea, whereas the mGluR5 agonist CHPG reduced the cell surviv to cells to $6.33 \%$. Treatment with black or green tea also increased the percentage of surviving cells (Fig. 6b).

\section{Involvement of $\mathrm{Ca}^{2+}$ in Prevention of Nerve Injury by Pu-erh Tea}

The activation of mGluR5 could increase $\mathrm{Ca}^{2+}$ influx, and excitotoxic $\mathrm{Ca}^{2+}$ elevation is an early and possibly reversible pathological event that may lead to neuronal injury. To investigate the role of pu-erh tea in $\mathrm{Ca}^{2+}$ release in nerve injury induced by L-Glu, SH-SY5Y cells were incubated with puerh tea before treated with L-Glu, using an intracellular $\mathrm{Ca}^{2+}$ chelator (Fluo-3 AM). Pretreatment with pu-erh tea significantly inhibited calcium influx compared to that black tea or green teas. However, mGluR5 CHPG activated the calcium influx (Fig. 6c).

\section{Pu-erh Tea Inhibited PKC $\alpha$ Activation by L-Glu}

In addition to $\mathrm{Ca}^{2+}$ release, $\mathrm{PKC} \alpha$ is involved in mGluR5 signalling. After nerve injury by L-Glu, we observed that $\mathrm{PKC} \alpha$ activity was increased. Moreover, pretreatment with the mGluR5 antagonist MPEP, inhibited PKC $\alpha$ activity. $\mathrm{Pu}-$ erh tea significantly reduced $\mathrm{PKC} \alpha$ activity compared to black or green teas. The content of PKC $\alpha$ in each group did not change. (Fig. 6d, e).

\section{Effect of Pu-erh Tea on Behaviour}

The Wistar rats that injected intraperitoneally with Liclpilocarpine only had obvious epilepsy behaviour, while the groups treated with pu-erh tea onLicl-pilocarpine induced SE significantly attenuated the maximal seizure classes and 

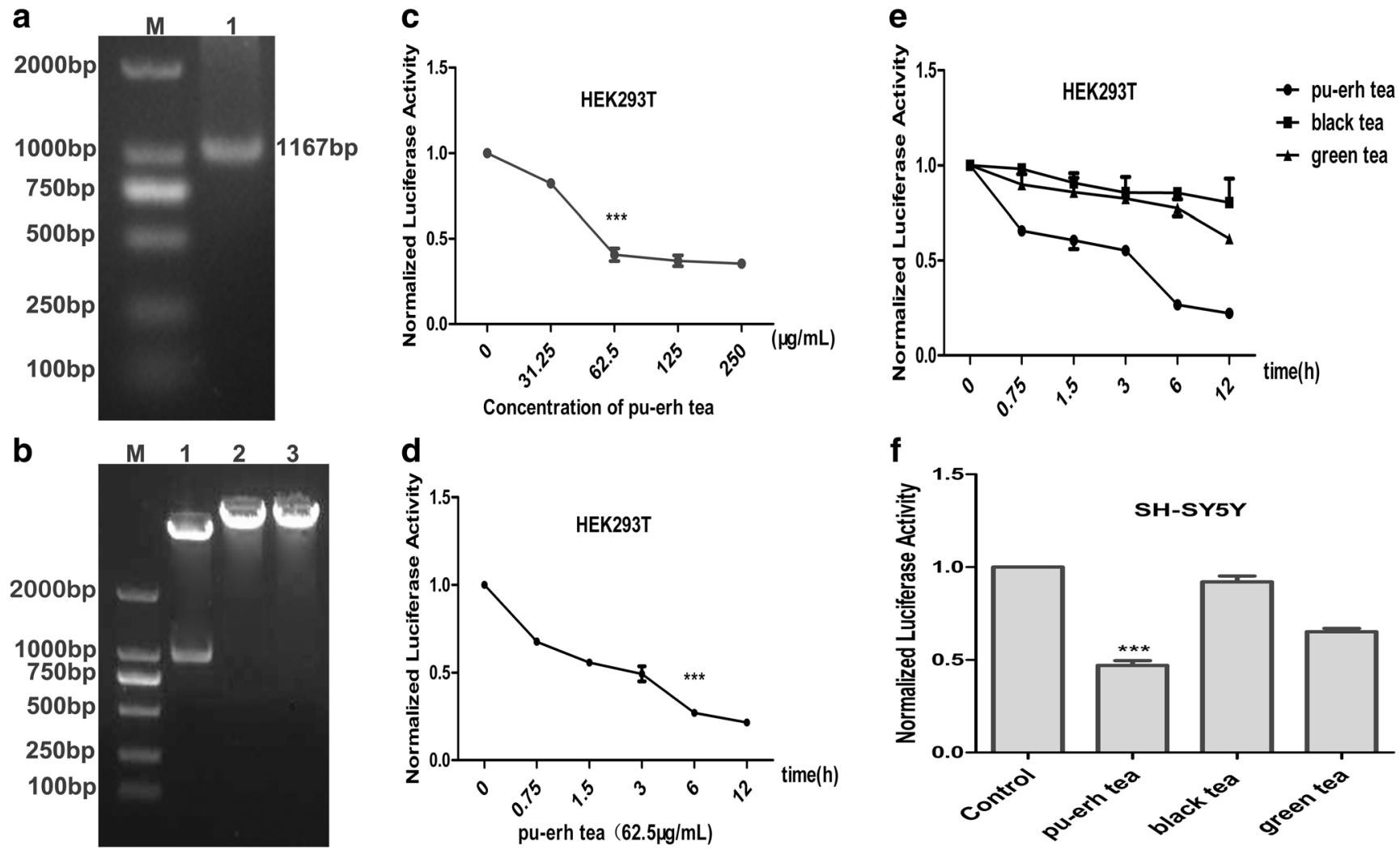

Fig. 4 a Agarose gel electrophoresis of mGluR5 promoter. M: 2000 DNA marker; 1:mGluR5 promoter PCR product. b Agarose gel electrophoresis of mGluR5 promoter-pGL3 double restriction enzyme digestion. M: $2000 \mathrm{bp}$; 1: mGluR5 promoter-pGL3 double restriction enzyme digestion; 2: mGluR5 promoter-pGL3 KpnI restriction enzyme digestion; 3: mGluR5 promoter-pGL3 HindIII restriction enzyme digestion. $\mathbf{c}$ Luciferase activity after treatment with various concentrations of

the predominant behavioural seizure patterns in SE mice compared with the control (Table 3, $n=6$ ).

\section{Pu-erh Tea Prevents Epilepsy by Inhibiting mGluR5}

IP3 and DAG, as second messengers, play important roles on in intracellular messenger transduction. These two substances stimulate neurons and can cause neuronal damage if present in excess. We accordingly assayed the contents of IP3 and DAG in the hippocampus by ELISA to confirm the effect of pu-erh tea on prevention of epilepsy. The results showed that IP3 and DAG were increased in epilepsy and decreased under intragastric administration of pu-erh tea (Fig. 7a, b). Histological images using HE staining showed that after epilepsy rat hippocampus showed injury, whereas before intragastric administration of pu-erh tea or diazepam, rat hippocampus showed no changes compared to the control (Fig. 7c).

To determine whether mGluR5 is implicated in epilepsy, we used immunofluorescence and Western blot assays. In the immunofluorescence assays, the expression of mGluR5 was significantly upregulated in epileptic rats only administrated

pu-erh tea for $12 \mathrm{~h}$. d Luciferase activity after treatment with $62.5 \mu \mathrm{g} / \mathrm{mL}$ pu-erh tea for various times. e Luciferase activity after treatment with $62.5 \mu \mathrm{g} / \mathrm{mL}$ pu-erh, black, green teas for various times. f Luciferase activity after treatment with $62.5 \mu \mathrm{g} / \mathrm{mL}$ pu-erh, black, green teas for 6 h. Data were analysed using the GraphPad Prism software $(* * * p<0.001$ vs. vehicle control, $n=6)$

intraperitoneally with Licl-pilocarpin compared to others, whereas the rats before intragastric administration of pu-erh tea or diazepam showed reduced expression of mGluR5 compared to that in epilepsy (Fig. 7d, e). In Western blot, we also found the similar result (Fig. 7f, g).

\section{Discussion}

In the present study, we observed that pu-erh tea decreased the mGluR 5 promoter activity and downregulated the expression of the mGluR5 at dose-dependently and time-dependently. We also discovered that pu-erh tea protected SH-SY5Y cells against apoptosis induced by L-glu via blocking $\mathrm{Ca}^{2+}$ influx and inhibiting the PKC $\alpha$ activation. Pu-er tea had the role of alleviating epilepsy and reducing the expression of mGluR5 in epilepsy rats.

Human epidemiological and animal research experiments suggest that the pharmacological benefits of tea drinking may help protect the brain. And tea drinking has been shown to exert neuroprotective activities in a wide array of cellular and animal models of neurological disorders [25]. The Affymetrix 

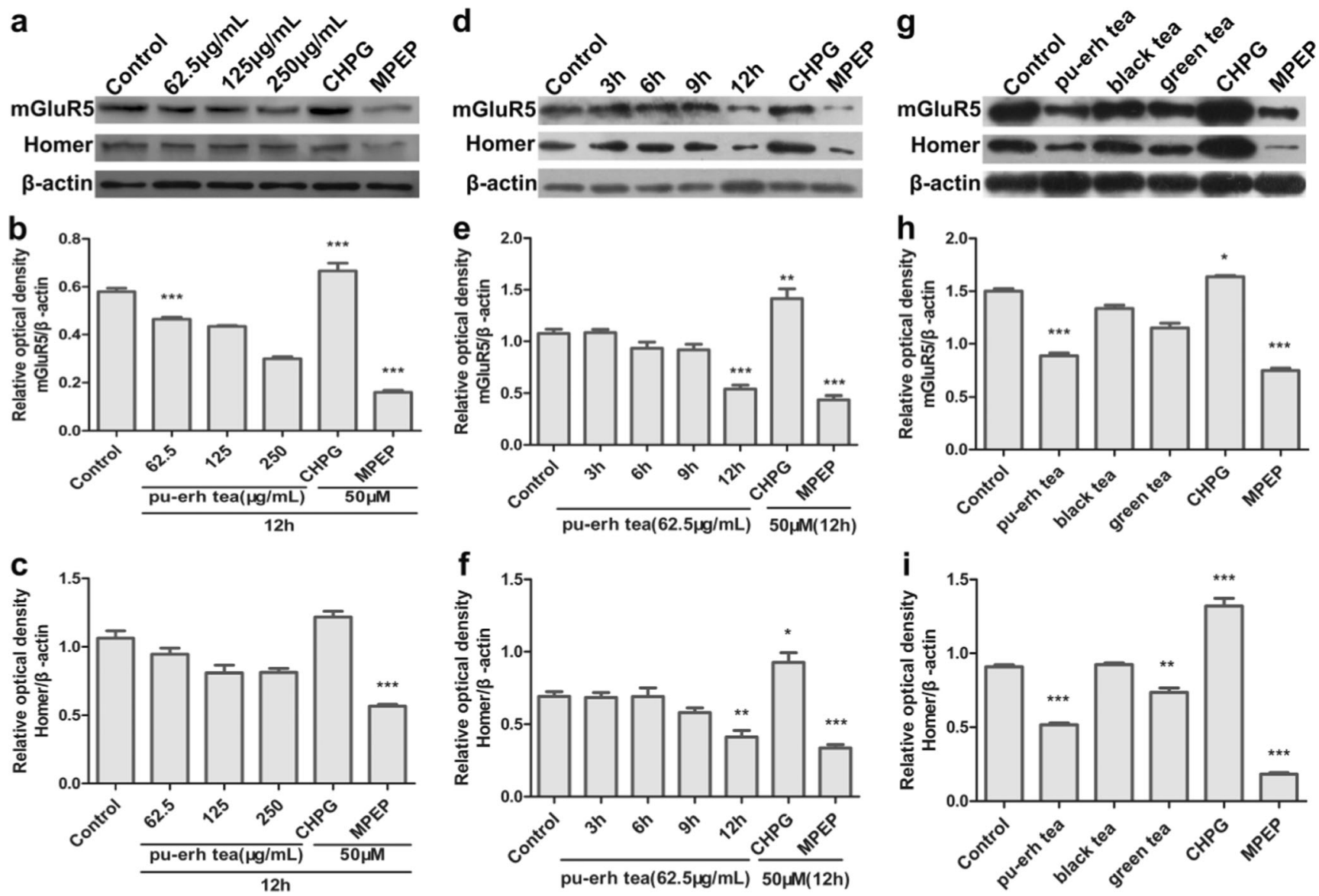

Fig. 5 The expression of mGluR5 and Homer were detected by Western blot and analysed by ImageJ. a-c Cells were treated with various concentrations of pu-erh tea for $12 \mathrm{~h}$. d-f Cells were treated with $62.5 \mu \mathrm{g} / \mathrm{mL}$ pu-erh tea for $3,6,9,12 \mathrm{~h}$. g-i Cells were treated with

expression microarrays showed that $0.25 \mathrm{mg} / \mathrm{mL}$ pu-erh tea decreased the mGluR5. Our results that pu-erh tea showed no toxicity to tumour cells and normal cells at low concentrations $(\leq 0.25 \mathrm{mg} / \mathrm{mL})$ was in accordance with the report that pu-erh tea showed no signs of toxicity and no deaths in SD rats at dosages $\leq 10 \mathrm{~g} / \mathrm{kg}$ [26]. These results indicated that the reduction of mGluR5 mRNA and protein by pu-erh tea was not the result of cell death at low concentration $(\leq 0.25 \mathrm{mg} / \mathrm{mL})$.

Excessive mGluR5 activation has already been alluded to as a potential contributing factor in synaptic disorders, and a number of studies are currently testing the therapeutic potential of drugs that modify mGluR5 [27]. The modification of particular mGluR5 has been implicated in synaptic diseases and psychiatric disorders [28]. Despite progress in drug treatment of schizophrenia, cognitive and other negative symptoms remain a major issue of the disease, often representing residual symptoms of resistant schizophrenia and being worsened by the side effects of antipsychotics effects [29].

The mGluR5 promoter we cloned could regulate the expression of luciferase (Fig. 4). It was consistent with the result
$62.5 \mu \mathrm{g} / \mathrm{mL}$ pu-erh, black, or green teas for $12 \mathrm{~h}$. Data were analysed using GraphPad Prism software $(* * * p<0.001$ vs. vehicle control, $* * p<0.01$ vs. vehicle control, $n=3$ )

that the alternative 5-splicing and usage of multiple promoters may contribute regulatory mechanisms for tissue- and context-specific expression of the mGluR5 gene [30]. The results of luciferase assays (Fig. 4) and Western blot (Fig. 5) suggested that pu-erh tea contains active compounds that could inhibit the transcription and the translation of mGluR5 compared to black tea and green tea. It may be during the fermentation, the types, activity and content of the components in pu-erh tea are different from those of black and green teas [31]. Owing to the complexity of the composition of puerh tea, the active ingredients that protect neural cells via reducing the expression of mGluR5 await further study. The mGluR5 agonist CHPG increased the expression of mGluR5 and an mGluR5 antagonist MPEP reduced the expression of mGluR5 (Fig. 5). These results suggested that pu-erh tea was a candidate as mGluR5 antagonist.

Importantly, the activity of mGluR5 is tightly regulated by its association with scaffolding protein, Homer [32]. In Western blot, we found that pu-erh tea could downregulate the expression of Homer significantly compared to black or green teas (Fig. 5). Homer proteins share a commom Ena/ 

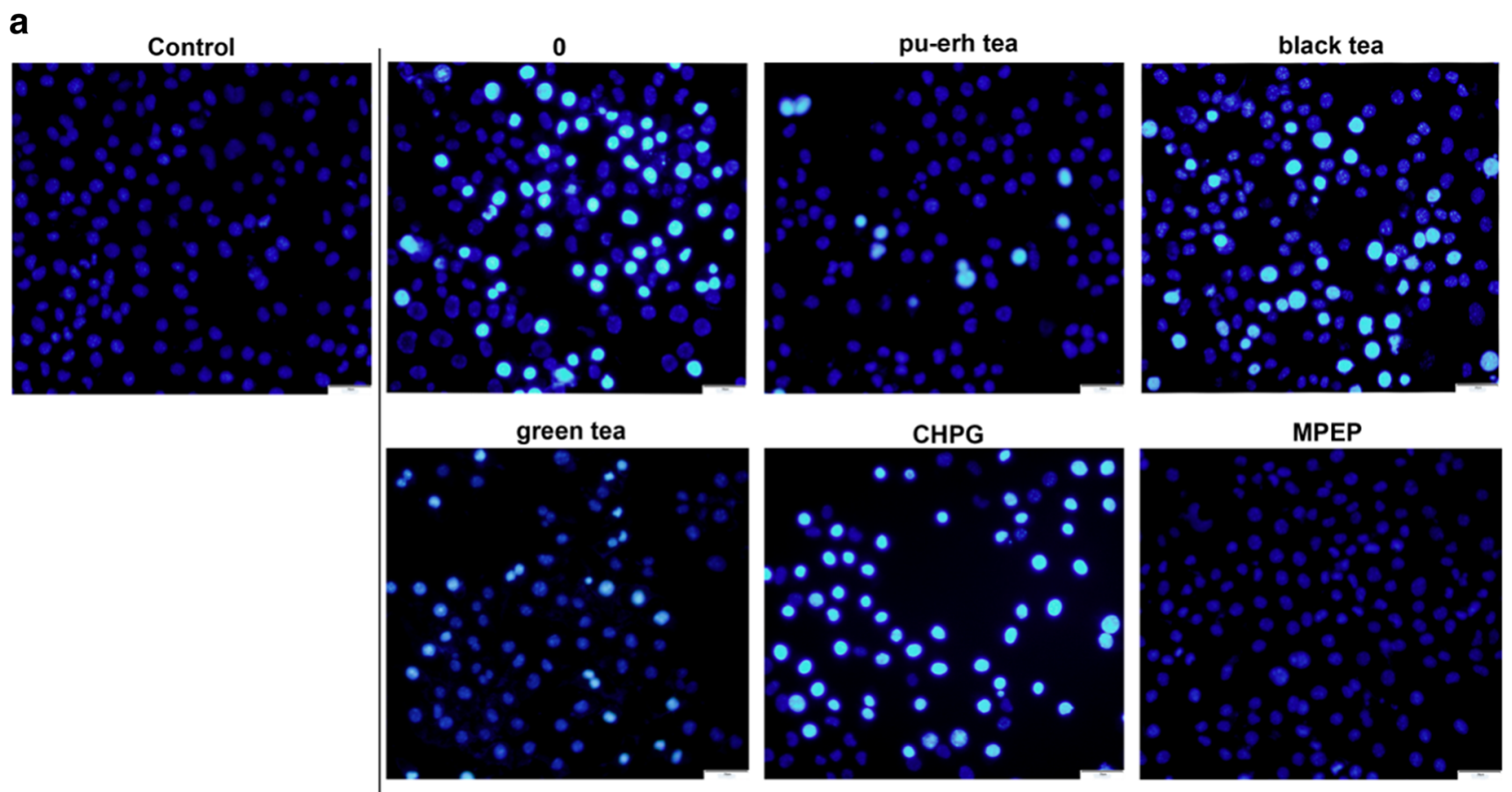

160mM L-Glu
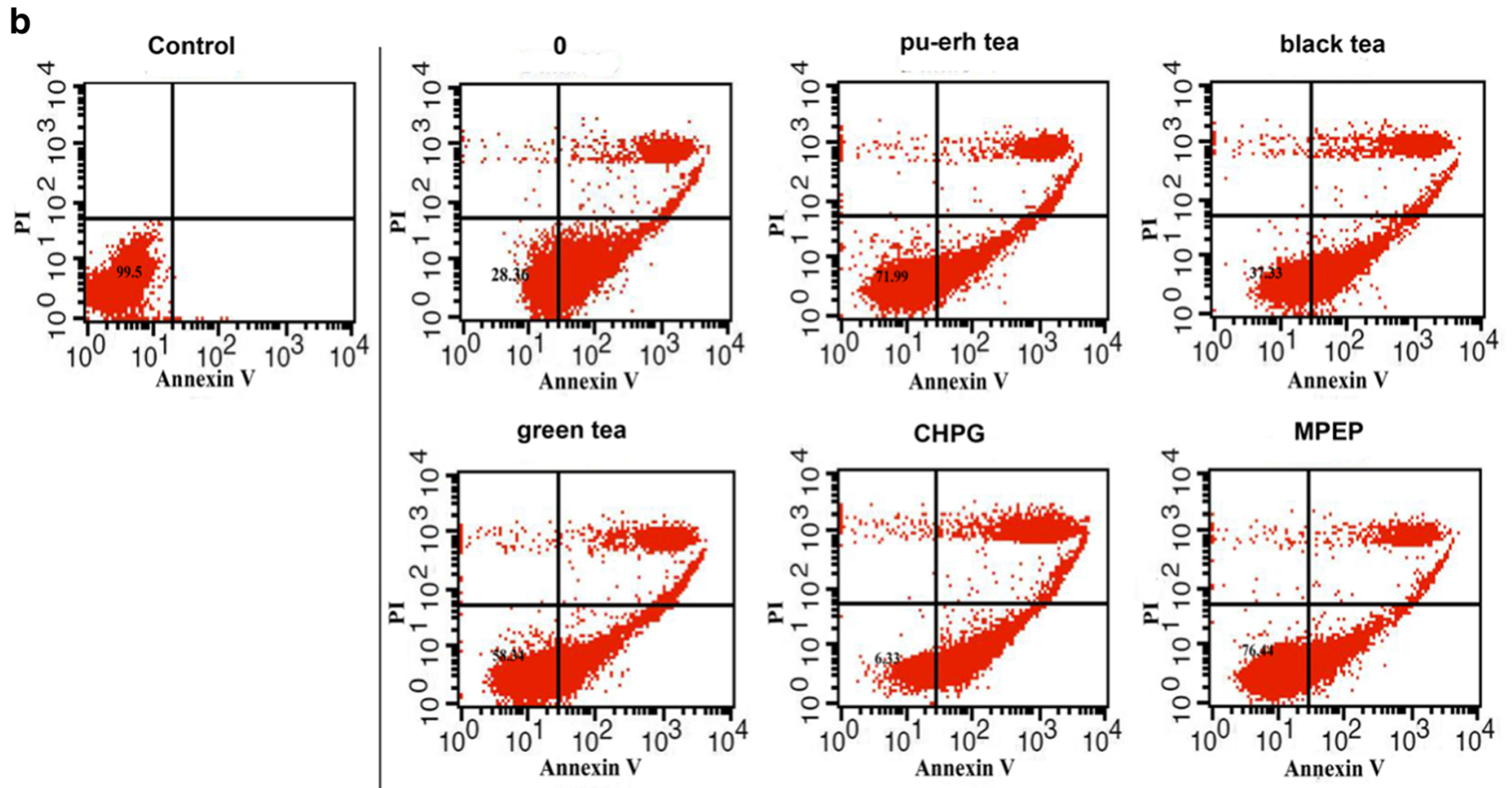

160mM L-Glu

Fig. 6 a Image of Hoechst 33342-stained cells. b Flow cytometry analysis of apoptosis. $\mathbf{c}$ Flow cytometry analysis of $\mathrm{Ca}^{2+}$ influx. $\mathbf{d}$ Western blot analysis of PKC $\alpha$ activity. e Quantification of protein level from three independent experiments using ImageJ. Cells were pretreated with

$62.5 \mu \mathrm{g} / \mathrm{mL}$ pu-erh, black, or green teas for $12 \mathrm{~h}$ before treatment with $160 \mathrm{mM} \mathrm{L}-$ Glu. Data were analysed using GraphPad Prism software $(* * * p<0.001, n=3)$

Vasp homology protein (EVH1) domain at the N-terminus that binds to the intracellular C-terminal tail of mGluR5 and localises mGluR5 to the postsynaptic density (PSD) $[6,33$, 34]. In addition, it has been shown that disruption of mGluR5-

Homer interactions selectively blocks mGluR5 activation [35]. These results indicated that the inhibition of mGluR5 by pu-erh tea disrupted mGluR5-Homer scaffolds, resulting in decreasing Homer. 

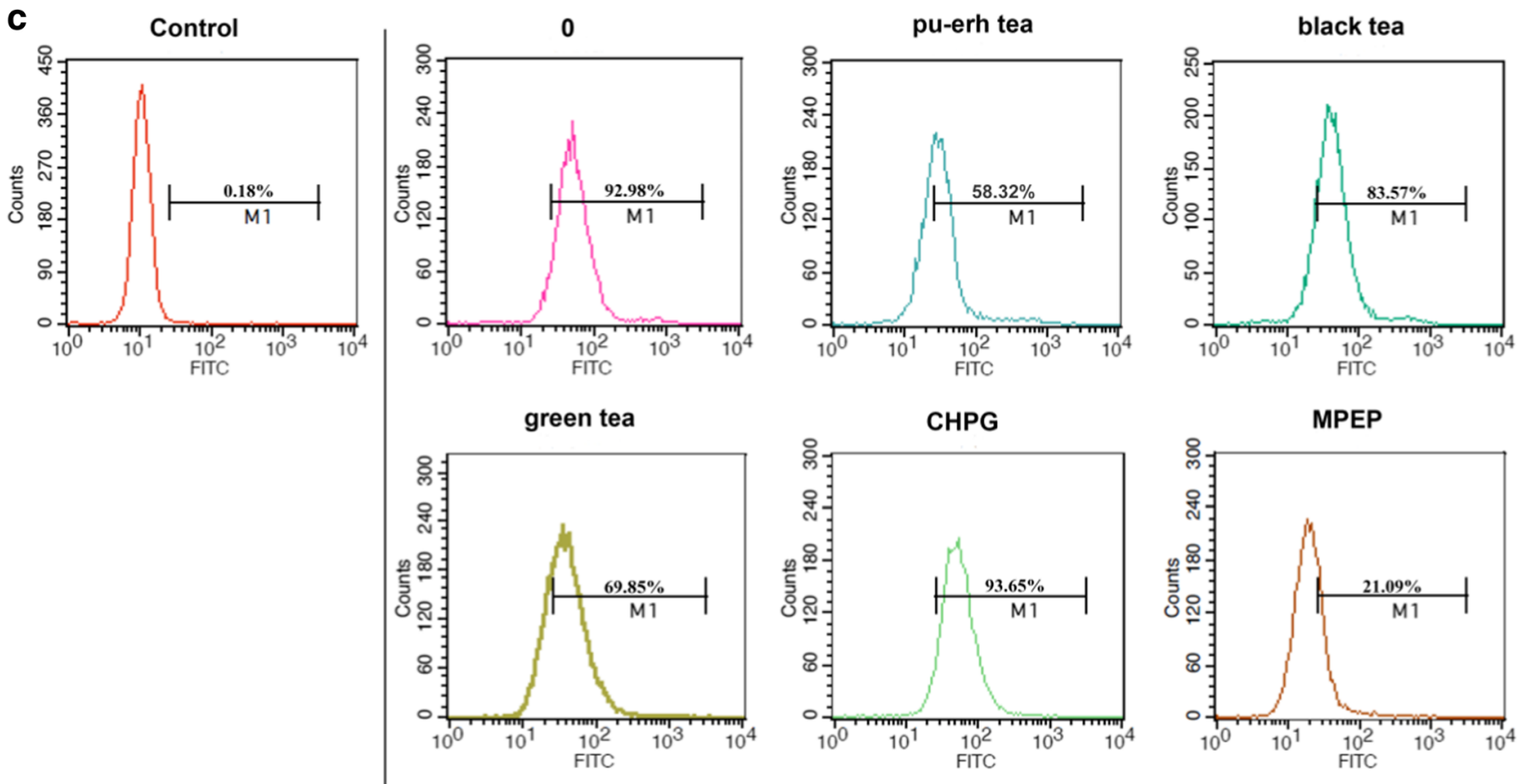

$160 \mathrm{mM}$ L-Glu

d

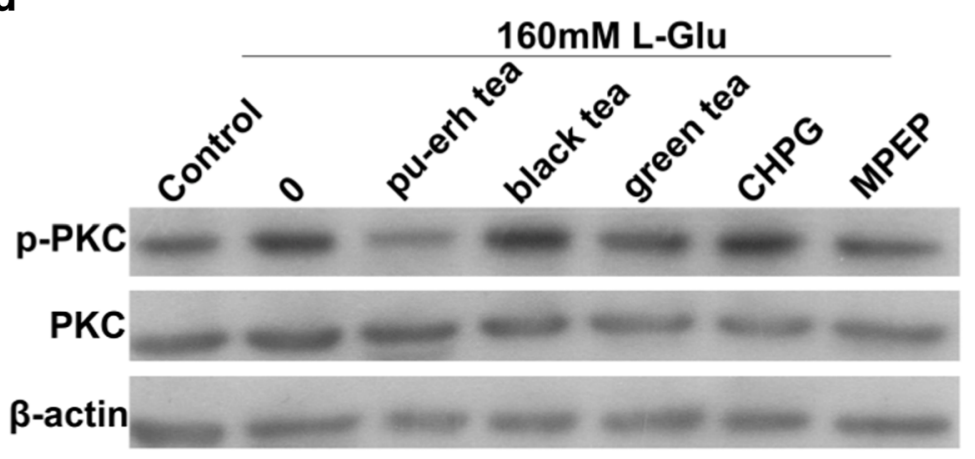

e

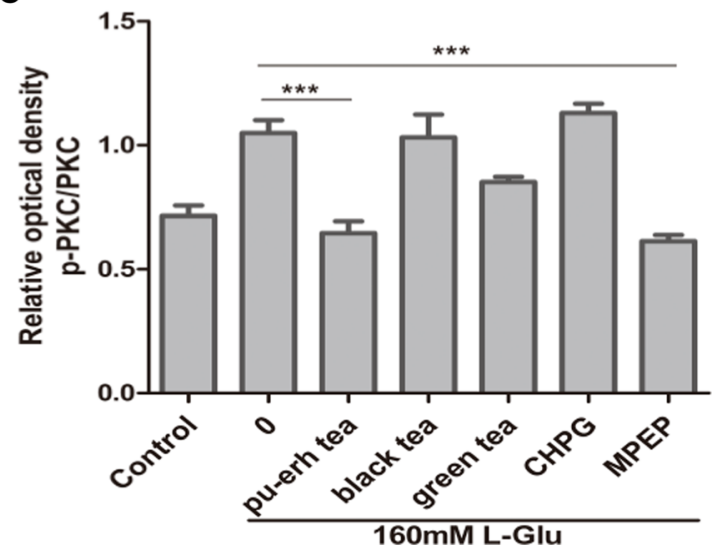

Fig. 6 continued.

A recent study suggests that enhanced mGluR5-Homer binding leads to a reduction in mGluR5-induced cytosolic $\mathrm{Ca}^{2+}$ increase [36]. However, in our study, both L-Glu and mGluR5 agonist CHPG induced nerve cell necrosis and increased intracellular $\mathrm{Ca}^{2+}$ response. These findings are in

Table 3 Effect of pu-erh tea on SE class

\begin{tabular}{llllllll}
\hline Pu-erh tea & & - & - & - & + & + & + \\
\hline LiCl-pilocarpine & & - & + & + & - & + & + \\
Diazepam & & - & - & + & - & - & + \\
Behaviour (times) & I/Class 1-2 & 0 & 32 & 5 & 0 & 8 & 4 \\
& M/Class 3 & 0 & 51 & 1 & 0 & 5 & 0 \\
& C/Class 4-6 & 0 & 64 & 0 & 0 & 0 & 0 \\
\hline
\end{tabular}

agreement with the report that Homer proteins bind IP3 receptor [37]. IP3 induces calcium release from intracellular stores, potentially leading to cell death [38]. Pretreatment with pu-erh tea or an mGluR5 antagonist MPEP could protect cells from necrosis and decrease intracellular $\mathrm{Ca}^{2+}$ response. These results suggested that pu-erh tea had the role of mGluR5 antagonist that prevented Homer binding IP3 receptor, which contributed to blocking the glutamate stimulation and inhibiting the release of intracellular $\mathrm{Ca}^{2+}$ in response to neuronal injury.

The mGluR5-induced $\mathrm{Ca}^{2+}$ response could also be negatively regulated by Homer 1a under some condition [39]. Given that group I mGluRs are positively coupled to PLC, leading to PKC activation and phosphorylation of serine 839 mediated by PKC activation is involved in the regulation of mGlu5 receptor-mediated $\mathrm{Ca}^{2+}$ influx [40, 41]. Therefore, 
a

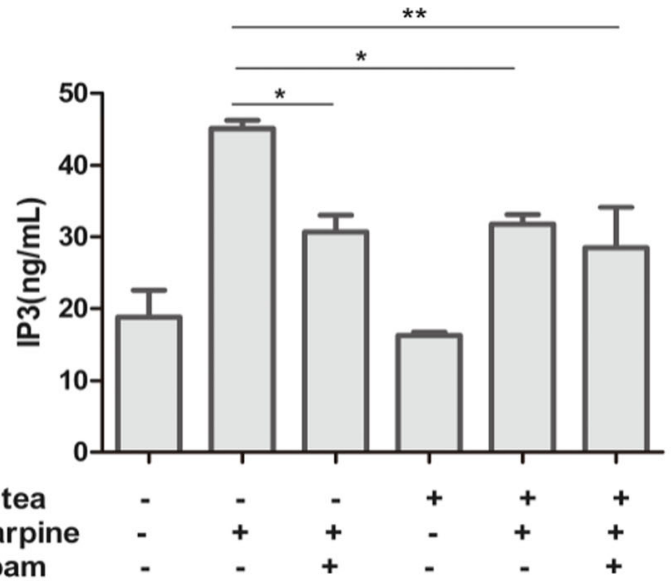

b

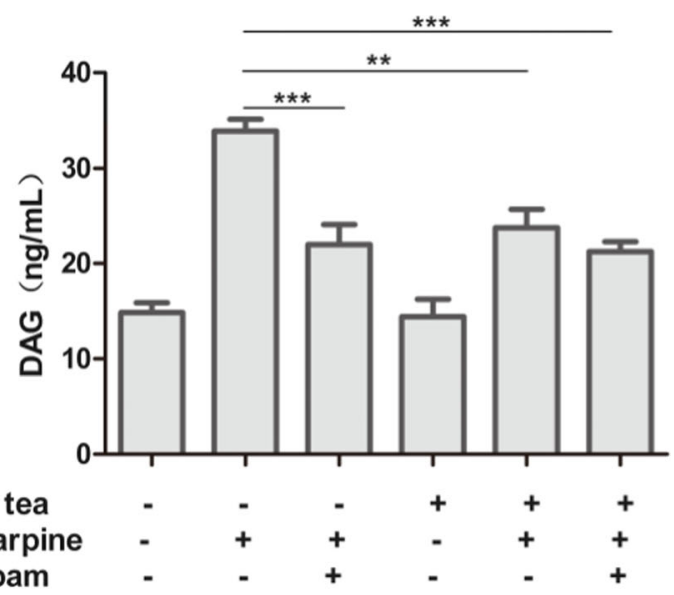

C

\section{Licl-pilocarpine \\ Diazepam}
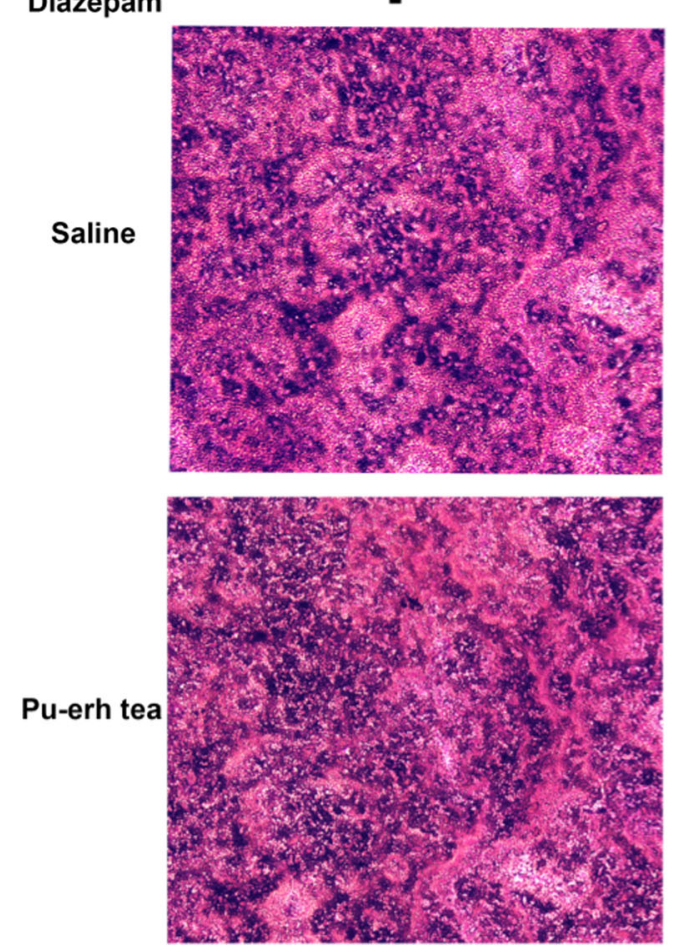

Fig.7 a Content of IP3 in the hippocampus. b Content of DAG in the hippocampus. $\mathbf{c}$ HE staining of hippocampus. d Immunofluorescence of hippocampus with Hochest 33,342 (blue) and anti-mGluR5 (green). e Quantification of relative fluorescence intensity of mGluR5/Hochest
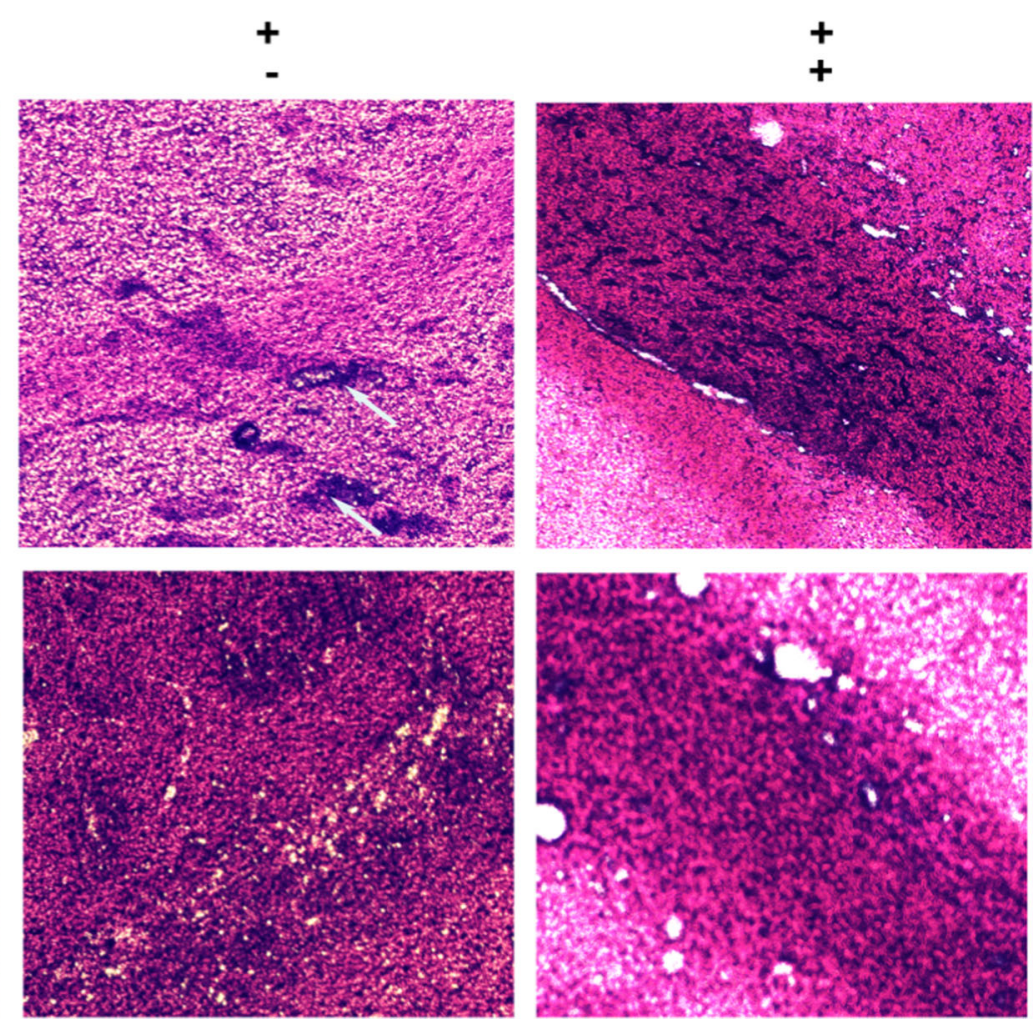

33342 by ImageJ. f Western blot analysis the expression of mGluR5 in the hippocampus. g Quantification of protein levels from three independent experiments by ImageJ. Data were analysed using GraphPad Prism software $(* * * p<0.001, * * p<0.01, * p<0.05, n=3)$ we wondered whether the ability of pu-erh tea to attenuate the release of intracellular was dependent mGluR5-PKC. We tested the activation of PKC $\alpha$ and found that both L-Glu and the mGluR5 agonist CHPG stimulated PKC activation, whereas pu-erh tea or an mGluR5 antagonist MPEP inhibited $\mathrm{PKC} \alpha$ activation. Thus, we theorise that pu-erh tea protected neuronal injury by inhibiting PKC activation which resulted from inhibiting the release of intracellular $\mathrm{Ca}^{2+}$. However, PKC isoenzymes have been classified into two subfamilies: the conventional subtypes (cPKC: $\alpha, \beta \mathrm{I}$, $\beta I I, \gamma)$ are $\mathrm{Ca}^{2+}$ and DAG-dependent and novel subtypes (nPKC: $\delta, \gamma, \eta, \theta$,) are DAG-dependent, but $\mathrm{Ca}^{2+}$-independent [42]. Group I mGluRs coupled to $\mathrm{G} \alpha \mathrm{q} / 11$ proteins stimulate the activation of PLC, resulting in DAG formation. Pu-erh tea decreased the contents of IP3 and DAG in the hippocampus (Fig. 7a, b). Accordingly, whether pu-erh tea influences the novel subtypes of PKC awaits further investigation. 
Fig. 8 The mechanism of pu-erh tea protects neural cell from injury stimulated by glutamate
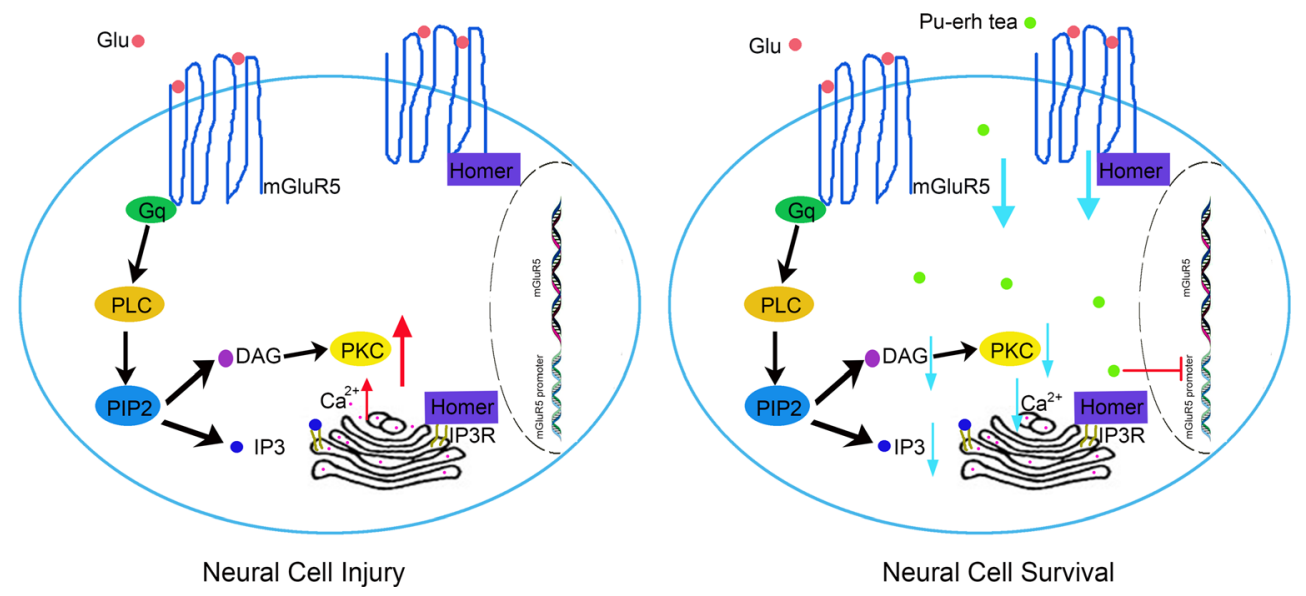

mGluR5 is well known to play important roles in neuronal function and synaptic plasticity, and defects in mGluR5 signals are thought to cause a variety of neurological disorders. Activation of mGluR5 increases epileptiform activity and an mGluR5 antagonist MPEP inhibits convulsive and nonconvulsive primary generalised seizures [43]. In this study, we constructed an epilepsy model by using Licl-pilocarpin [21]. Pilocarpine activates the G-protein which mediates the receptor stimulation to PLC. PLC hydrolyses PI into IP3 and DAG. IP3 and DAG cause neuronal stimulation and when in excess, may contribute to neuronal injury [44]. In general, mGluR5 combined with glutamate activates the G-protein $\mathrm{Gq} / 11$, and subsequently, the activated G-protein activates PLC which hydrolyses membrane phosphoinositides to form IP3 and DAG [5]. We found that pu-erh tea could decrease the severity of seizure behaviours and the content of IP3 and DAG. Immunofluorescence and Western blot both showed that pu-erh tea reduced the expression of mGluR5 that was increased in epilepsy rats. These results coincide with that the expression of mGluR5 is higher in the hippocampus of epileptic patients, than in those of a control group [45]. The results indicated that pu-erh tea could decrease the content of IP3 and DAG through reducing the expression of mGluR5. Taken together, these results indicate that pu-erh tea played an important role in protecting neural cells from injury induced by glutamate and antiepileptic via inhibiting the activity of mGluR5 promoter and the expression of mGluR5 (Fig. 8).

\section{Conclusion}

Dysregulation of mGluR5 is implicated in multiple brain disorders. Accordingly, many selective mGluR5 antagonists have been developed for clinical therapy. However, these drugs have produced unacceptable side effects in clinical trials. The findings of this study suggested that pu-erh tea can inhibit mGluR5 activation stimulated by glutamate via inhibiting the activity of mGluR5 promoter and the expression of mGluR5, which blocks $\mathrm{Ca}^{2+}$ influx and suppresses the activity of PKC $\alpha$ to protect nerve cell from necrosis. Pu-erh tea also relieves rat epilepsy and reduce the contents of IP3 and DAG in epilepsy rats. These results suggest that pu-erh tea is a potential neuroprotective agent acting via regulation of mGluR5. However, the specific compounds in pu-erh tea that function in neural protection await further study.

Acknowledgments We appreciate the Pu-erh Tea Research Institute for pu-erh tea. This study was supported by grants from the National Nature Science Foundation of China (no. 51473060), Science and Technology Department of Jilin Province (no. 20130206010YY) and Pu-erh Tea Research Institute (no. 2013220101001352).

Author Contributions The experiments were designed by Chunjie Li, Jun Sheng and Wei Shi and performed in the laboratory of Wei Shi. Puerh tea was supplied by Jun Sheng. The date was collected and analysed by Chunjie Li and Hang Zhao. Flow cytometry experiments were performed by Chunjie Li and Shaomeng Chai. Animal experiments were performed by Chunjie Li, Yongzhi Ju and Tian Li. The manuscript was written by Chunjie Li, Lu Hou, Wei Ma and Wei Shi. All authors read and approved the final version.

Open Access This article is distributed under the terms of the Creative Commons Attribution 4.0 International License (http:// creativecommons.org/licenses/by/4.0/), which permits unrestricted use, distribution, and reproduction in any medium, provided you give appropriate credit to the original author(s) and the source, provide a link to the Creative Commons license, and indicate if changes were made.

\section{References}

1. Robbins TW, Murphy ER (2006) Behavioural pharmacology: 40+ years of progress, with a focus on glutamate receptors and cognition. Trends Pharmacol Sci 27(3):141-148. doi:10.1016/j. tips.2006.01.009

2. Moghaddam B, Javitt D (2012) From revolution to evolution: the glutamate hypothesis of schizophrenia and its implication for treatment. Neuropsychopharmacology 37(1):4-15. doi:10.1038 /npp.2011.181

3. Power EM, English NA, Empson RM (2016) Are type 1 metabotropic glutamate receptors a viable therapeutic target for the treatment of cerebellar ataxia? J Physiol. doi:10.1113/JP271153 
4. Niswender CM, Conn PJ (2010) Metabotropic glutamate receptors: physiology, pharmacology, and disease. Annu Rev Pharmacol Toxicol 50:295-322. doi:10.1146/annurev. pharmtox.011008.145533

5. Matosin N, Newell KA (2013) Metabotropic glutamate receptor 5 in the pathology and treatment of schizophrenia. Neurosci Biobehav Rev 37(3):256-268. doi:10.1016/j. neubiorev.2012.12.005

6. Shiraishi-Yamaguchi Y, Furuichi T (2007) The Homer family proteins. Genome Biol 8(2):206. doi:10.1186/gb-2007-8-2-206

7. Krystal JH et al. (2010) Potential psychiatric applications of metabotropic glutamate receptor agonists and antagonists. CNS Drugs 24(8):669-693. doi:10.2165/11533230-000000000-00000

8. Bruno Vet al. (2000) Selective blockade of metabotropic glutamate receptor subtype 5 is neuroprotective. Neuropharmacology 39(12): 2223-2230

9. Schmidt D, Schachter SC (2014) Drug treatment of epilepsy in adults. BMJ 348:g254. doi:10.1136/bmj.g254

10. Loscher W, Schmidt D (2011) Modern antiepileptic drug development has failed to deliver: ways out of the current dilemma. Epilepsia 52(4):657-678. doi:10.1111/j.15281167.2011.03024.x

11. Loscher W (2002) Current status and future directions in the pharmacotherapy of epilepsy. Trends Pharmacol Sci 23(3): 113-118. doi:10.1016/S0165-6147(00)01974-X

12. Jeng $\mathrm{KC}$ et al. (2007) Effect of microbial fermentation on content of statin, GABA, and polyphenols in Pu-erh tea. J Agric Food Chem 55(21):8787-8792. doi:10.1021/jf071629p

13. $\mathrm{Xu} \mathrm{Y}$ et al. (2011) Variations of antioxidant properties and NO scavenging abilities during fermentation of tea. Int J Mol Sci 12(7):4574-4590. doi:10.3390/ijms12074574

14. Ding $\mathrm{Y}$ et al. (2015) Pu-erh tea down-regulates sterol regulatory element-binding protein and stearyol-CoA desaturase to reduce fat storage in Caenorhaditis elegans. PLoS One 10(2):e0113815. doi:10.1371/journal.pone.0113815

15. Lin JK, Lin-Shiau SY (2006) Mechanisms of hypolipidemic and anti-obesity effects of tea and tea polyphenols. Mol Nutr Food Res 50(2):211-217. doi:10.1002/mnfr.200500138

16. Su Y et al. (2012) Antibacterial property and mechanism of a novel $\mathrm{Pu}$-erh tea nanofibrous membrane. Appl Microbiol Biotechnol 93(4):1663-1671. doi:10.1007/s00253-011-3501-2

17. Zhao $\mathrm{H}$ et al. (2011) Changes of constituents and activity to apoptosis and cell cycle during fermentation of tea. Int $\mathrm{J}$ Mol Sci 12(3):1862-1875. doi:10.3390/ijms12031862

18. $\mathrm{Xu} \mathrm{Y}$ et al. (2012) Pu-erh tea reduces nitric oxide levels in rats by inhibiting inducible nitric oxide synthase expression through toll-like receptor 4. Int J Mol Sci 13(6):7174-7185. doi:10.3390/ijms 13067174

19. Hou CW (2011) Pu-erh tea and GABA attenuates oxidative stress in kainic acid-induced status epilepticus. J Biomed Sci 18:75. doi:10.1186/1423-0127-18-75

20. $\mathrm{Yu} \mathrm{Y}$ et al. (2014) Pu-erh tea extract induces the degradation of FET family proteins involved in the pathogenesis of amyotrophic lateral sclerosis. Biomed Res Int 2014:254680. doi: $10.1155 / 2014 / 254680$

21. Grabenstatter HL et al. (2014) Effect of spontaneous seizures on GABAA receptor alpha4 subunit expression in an animal model of temporal lobe epilepsy. Epilepsia 55(11):1826-1833. doi:10.1111 /epi.12771

22. Racine RJ (1972) Modification of seizure activity by electrical stimulation. II. Motor seizure. Electroencephalogr Clin Neurophysiol 32(3):281-294

23. Luo P et al. (2014) Postsynaptic scaffold protein Homer 1a protects against traumatic brain injury via regulating group I metabotropic glutamate receptors. Cell Death Dis 5:e1174. doi:10.1038 /cddis. 2014.116

24. Zhai MZ et al. (2016) Dexmedetomidine dose-dependently attenuates Ropivacaine-induced seizures and negative emotions via inhibiting phosphorylation of amygdala extracellular signal-regulated kinase in mice. Mol Neurobiol 53(4): 2636-2646. doi:10.1007/s12035-015-9276-1

25. Mandel SA et al. (2008) Targeting multiple neurodegenerative diseases etiologies with multimodal-acting green tea catechins. J Nutr 138(8):1578S-1583S

26. Wang D et al. (2011) Acute and subchronic oral toxicities of $\mathrm{Pu}$ erh black tea extract in Sprague-Dawley rats. J Ethnopharmacol 134(1):156-164. doi:10.1016/j.jep.2010.11.068

27. Dolen $\mathrm{G}$ et al. (2010) Mechanism-based approaches to treating fragile X. Pharmacol Ther 127(1):78-93. doi:10.1016/j. pharmthera.2010.02.008

28. Piers TM et al. (2012) Translational concepts of mGluR5 in synaptic diseases of the brain. Front Pharmacol 3:199. doi:10.3389 /fphar.2012.00199

29. de Bartolomeis A et al. (2012) Targeting glutamate system for novel antipsychotic approaches: relevance for residual psychotic symptoms and treatment resistant schizophrenia. Eur J Pharmacol 682(13):1-11. doi:10.1016/j.ejphar.2012.02.033

30. Corti $\mathrm{C}$ et al. (2003) Gene structure of the human metabotropic glutamate receptor 5 and functional analysis of its multiple promoters in neuroblastoma and astroglioma cells. J Biol Chem 278(35):33105-33119. doi:10.1074/jbc.M212380200

31. Wang D et al. (2010) Comparative safety evaluation of Chinese Puerh green tea extract and Pu-erh black tea extract in Wistar rats. J Agric Food Chem 58(2):1350-1358. doi:10.1021/j9902171h

32. Ronesi JA et al. (2012) Disrupted Homer scaffolds mediate abnormal mGluR5 function in a mouse model of fragile $\mathrm{X}$ syndrome. Nat Neurosci 15(3):431-440 . doi:10.1038 /nn.3033S1

33. Hayashi MK, Ames HM, Hayashi Y (2006) Tetrameric hub structure of postsynaptic scaffolding protein homer. J Neurosci 26(33):8492-8501. doi:10.1523/JNEUROSCI.273106.2006

34. Hayashi MK et al. (2009) The postsynaptic density proteins Homer and Shank form a polymeric network structure. Cell 137(1):159 171. doi:10.1016/j.cell.2009.01.050

35. Ronesi JA, Huber KM (2008) Homer interactions are necessary for metabotropic glutamate receptor-induced long-term depression and translational activation. J Neurosci 28(2): 543-547. doi:10.1523/JNEUROSCI.5019-07.2008

36. $\mathrm{Hu} \mathrm{JH}$ et al. (2012) Presol dynamically regulates group I metabotropic glutamate receptors. Nat Neurosci 15(6):836-844. doi:10.1038/nn.3103

37. Tu JC et al. (1998) Homer binds a novel proline-rich motif and links group 1 metabotropic glutamate receptors with IP3 receptors. Neuron 21(4):717-726

38. Power JM, Sah P (2007) Distribution of IP3-mediated calcium responses and their role in nuclear signalling in rat basolateral amygdala neurons. J Physiol 580(Pt.3):835-857. doi:10.1113 /jphysiol.2006.125062

39. Tappe A et al. (2006) Synaptic scaffolding protein Homerla protects against chronic inflammatory pain. Nat Med 12(6):677-681. doi:10.1038/nm1406

40. Nakanishi S (1994) Metabotropic glutamate receptors: synaptic transmission, modulation, and plasticity. Neuron 13(5): 1031-1037

41. Kim CH et al. (2005) Protein kinase C phosphorylation of the metabotropic glutamate receptor mGluR5 on serine 839 regulates Ca2+ oscillations. J Biol Chem 280(27):25409-25415. doi:10.1074 /jbc.M502644200 
42. Parker PJ, Murray-Rust J (2004) PKC at a glance. J Cell Sci $117(\mathrm{Pt}$ 2):131-132. doi:10.1242/jcs.00982

43. Chapman AG et al. (2000) Anticonvulsant activity of two metabotropic glutamate group I antagonists selective for the $\mathrm{mGlu} 5$ receptor: 2-methyl-6-(phenylethynyl)-pyridine (MPEP), and (E)-6-methyl-2styryl-pyridine (SIB 1893. Neuropharmacology 39(9):1567-1574
44. Savolainen KM, Hirvonen MR (1992) Second messengers in cholinergic-induced convulsions and neuronal injury. Toxicol Lett $64-65: 437-445 \mathrm{Spec}$ No

45. Notenboom RG et al. (2006) Up-regulation of hippocampal metabotropic glutamate receptor 5 in temporal lobe epilepsy patients. Brain 129(Pt 1):96-107. doi:10.1093/brain/awh673 